TABLE III.-Shoning the Death-rates recorded among Handfed Children according to the Kind of Food used.

\begin{tabular}{|c|c|c|c|}
\hline Kind of food used. & $\begin{array}{c}\text { Total } \\
\text { number } \\
\text { fed on each } \\
\text { food. }\end{array}$ & Deaths. & $\begin{array}{l}\text { Death-rate } \\
\text { per } 1000 \\
\text { fed on each } \\
\text { food. }\end{array}$ \\
\hline Milk-and-water only & 895 & 158 & 177 \\
\hline $\begin{array}{lll}\text { Condensed milk only } & \ldots & \ldots\end{array}$ & 149 & 38 & 255 \\
\hline $\left.\begin{array}{l}\text { Bread, rusks, oatmeal, arrow- } \\
\text { root, cornflour, sago, } \\
\text { tapioca, and mixed foods... }\end{array}\right\}$ & 159 & 40 & 252 \\
\hline $\begin{array}{llllll}\text { Patent food A } & \ldots & \ldots & \ldots & \ldots\end{array}$ & 39 & 7 & 180 \\
\hline $\begin{array}{llllll}\eta & \mathbf{B} & \ldots & \ldots & \ldots & \ldots\end{array}$ & 81 & 17 & 210 \\
\hline $\begin{array}{llllll} & \mathrm{C} & \ldots & \ldots & \ldots & \ldots\end{array}$ & 45 & 6 & 134 \\
\hline $\begin{array}{lllllll}, & , & \mathrm{D} & \ldots & \ldots & \ldots & \ldots\end{array}$ & 93 & 19 & 204 \\
\hline Various patent foods $\quad \ldots \quad \ldots$ & 164 & 36 & 220 \\
\hline $\begin{array}{lllll}\text { All patent foods... } & \ldots & \ldots & \ldots\end{array}$ & (422) & (85) & (202) \\
\hline Incomplete information... ... & 1 & 0 & 0 \\
\hline $\begin{array}{lllll}\text { Totals } & \ldots & \ldots & \ldots & \ldots\end{array}$ & 1626 & 321 & 198 \\
\hline
\end{tabular}

From this table it will be seen that the lowest death-rate was among children fed on patent food "C," after which children who were fed on milk-and-water survived in greatest proportion. In the aggregate the various patent foods show a death-rate of 202 per 1000 , as compared with 177 for milk-and-water. The composition of these foods is interesting when considered in relation to these statistical details; it shows that very many more children survive who are brought up on malted food in which there is no starch than on such as contains unconverted starch in marked degree, whilst occupying a middle position between the two are the various foods prepared from desiccated cows' milk. Patent food " $\mathrm{C}$ " is a farinaceous food in which the whole of the starch has been rendered soluble. It contains no fat; this is supplied by the milk used in preparing it. Patent food "A" contains no starch and is a very fair imitation of human milk. It approximates the composition of dried human milk but is deficient in both proteids and fat. Patent food "D" contains starch which has not been predigested and although perhaps even very young children can digest a certain amount of starch it is not a suitable food before the period of dentition. It is this class of food which forms a large proportion of those classified under "Various patent foods," and, as the results show, they are much less suited for children than the other two.

Children fed on condensed milk show a very high mortality - viz., 255 deaths per 1000 of children so fed-and this is not surprising. The chief reason is, perhaps, to be found in the analyses of these milks, which are as follows : ${ }^{2}$ -

\begin{tabular}{|c|c|c|c|c|c|c|c|c|}
\hline & \multicolumn{2}{|c|}{ Proteids. } & & \multicolumn{3}{|c|}{ Milk sugar. } & \multicolumn{2}{|c|}{ Cane su } \\
\hline ilk (ave & $1 \cdot 5$ & $\ldots$ & $3 \cdot 5$ & & $6 \cdot 5$ & $\ldots$ & ... & - \\
\hline Cows' milk & $2 \cdot 5$ & $\ldots$ & $4 \cdot 0$ & ... & 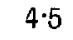 & & & \\
\hline $\begin{array}{l}\text { (cows' milk, } 2 \text { parts } ; \\
1 \text { part) }\end{array}$ & $1 \cdot 6$ & $\cdots$ & $2 \cdot 6$ & ... & $3 \cdot 0$ & $\cdots$ & & \\
\hline 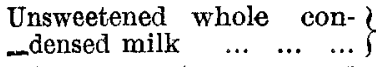 & $8 \cdot 3$ & ... & $12 \cdot 4$ & $\ldots$ & $16 \cdot 0$ & $\cdots$ & $\cdots$ & \\
\hline $\begin{array}{r}\text { (unsweetened } \\
\text { ondensed milk, } 1 \\
\text { ater, } 4 \text { parts) }\end{array}$ & $1 \cdot 7$ & ... & $2 \cdot 5$ & ... & $3 \cdot 2$ & ... & $\cdots$ & - \\
\hline $\left.\begin{array}{rl}\text { ned whole condensed } \\
\left.\begin{array}{rllll}\ldots & \ldots & \ldots & \ldots & \ldots\end{array}\right\}\end{array}\right\}$ & $9 \cdot 7$ & .. & $13 \cdot 7$ & ... & $15 \cdot 0$ & 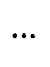 & .. & $37 \cdot 2$ \\
\hline Condensed separated milk & (* & & $2 \cdot 0$ & $\ldots$ & $13 \cdot 0$ & .. & $\ldots$ & $45^{\circ}$ \\
\hline
\end{tabular}

Unsweetened whole condensed milk if no fat has been extracted, constitutes as suitable an article as cows' milk from which to prepare food for infants, and if care is taken in sufficiently diluting it and making suitable additions no serious objection can be raised against its use, but the fact remains that for some reason or other practically none is used for feeding infants in this town. Analysis shows that to sweetened condensed milk a large amount of cane sugar is added, so that if this milk is diluted to the proportions necessary to bring the proteids and fat to the same standard as average human milk, sugar is in excessive proportion. Condensed separated milk shows almost the same percentage composition as sweetened whole condensed milk, except that the fat is reduced to 2 per cent. Such a milk is absolutely unsuited for the food of infants and its continuous use

${ }^{2}$ Food and the Principles of Dieteties, by Dr. Robert Hutchison; and Milk and Milk Products, by Permain and Moore. results in slow starvation of the infant. The death-rate among children reared on bread, rusks, arrowroot, and other farinaceous foods is exceedingly high, being 252 per 1000 . This is only what would be expected.

A death-rate of 177 per 1000 amongst children fed on modified milk is not satisfactory. The causes may in brief be stated to be twofold-first, the results of contamination, and secondly, the results of ignorance. The index to the effects of contamination may roughly be stated to be the deaths from diarrhcea and epidemic enteritis, and from ignorance the deaths from various disorders of digestionviz., gastritis and gastro-enteritis, marasmus and atrophy, and debility. The deaths from the former diseases total 84 and from the latter 74 , but to these must be added those resulting from impaired resistance which are the direct consequence of improper feeding, and the fact should not be lost sight of that though contamination acts most disastrously during a limited period of the year, the effects of ignorance are always in operation and, in the aggregate, are probably much more serious.

A consideration of the various ways in which contamination of the milk may result and of the means by which ignorance may be combated is not within the scope of this paper, but two points do seem worthy of reference. One is that the risk of contamination of milk in the homes of the poor in towns where privy middens are a feature is a serious one and it ought to be possible to enforce proper cupboard accommodation for the storage of food. The other is that, although education of girls at school in the subjects of domestic economy and home nursing would be of the greatest value, a very great deal more can be done by instructing the young mother at home as soon as possible after the baby has made its appearance. To do this would necessitate the notification of every birth to the sanitary authority and visitation by a properly qualified person. Such information is received in this town and visits are made with, I believe, the greatest advantage to both mother and child.

The deductions which it appears justifiable to draw from the mortality observed amongst hand-fed children fed on different foods are: that the use of sweetened condensed milk, either whole or skimmed, should be invariably discouraged and whole unsweetened condensed milk should only be permitted when one is satisfied that the milk is being used with a proper degree of dilution and with the necessary additions as in the case of modified cows' milk; also that since the death-rate amongst children reared on patent foods is, on the average, higher than amongst those fed on diluted cows' milk, every attempt should be made to encourage parents to use this latter food and to educate them to an appreciation of the necessity for the additions to, and the dilution of, cows' milk to render it suitable for infant's food. The addition of patent foods to the dietary of very young infants is unnecessary, sometimes dangerous, and always expensive.

In conclusion, it is unnecessary further to emphasise the risks to which hand-fed children are exposed, but it should not be forgotten that these risks are considerably minimised by mixed feeding and that, therefore, every mother who is unable fully to satisfy her infant should be encouraged to continue to feed her child and to supplement any deficiency by means of artificial food and that only in case of absolute and unavoidable necessity should resort be had to handfeeding alone.

Derby.

SOME REMARKS ON

THREE CASES OF SEPARATION OF THE DESCENDING PROCESS OF THE UPPER TIBIAL EPIPHYSIS IN ADOLESCENTS.

BY G. H. MAKINS, C.B., F.R.C.S. ENG., SURGEON TO ST. THOMAS'S HOSPITAL, ETC.

THIS condition, although not uncommon, has only been generally recognised since the use of the $x$ rays has become habitual in cases of bone injury or disease, although one can recall many mysterious instances of "enlargement of the tibial tubercle" in old "out-patient" experience. The following three cases illustrate growing knowledge on the subject. The first, seen in 1897, was mistaken for one of 
osseous tuberculosis, while in the light of the information gained in its treatment the succeeding two were placed in their proper category.

CASE 1. - The patient, a stout, somewhat flabby boy, aged 14 years, had received a kick over the upper end of the right tibia while playing football a year previously to being seen by me. This injury was followed by severe local pain which persisted for some time and on its cessation as a continuous trouble it recurred with any severe exercise and also occasionally in the form of aching when in bed at night. After the lapse of eight months some local swelling with intermittent pain developed and three weeks before the boy came under my care tincture of iodine was applied which caused slight redness of the overlying skin. A blister was then applied and this was followed by considerable diminution of the local swelling. In November, 1897, the following condition existed. An area of local swelling about one inch in diameter lay over the outer aspect of the tibial tubercle; this was tender on palpation and a sense of deep fluctuation could be obtained. The swelling was strictly localised and there had been no pain since the application of the blister. A skiagram (Fig. 1) was taken by the late Dr. Barry Blacker.

FIG. 1.

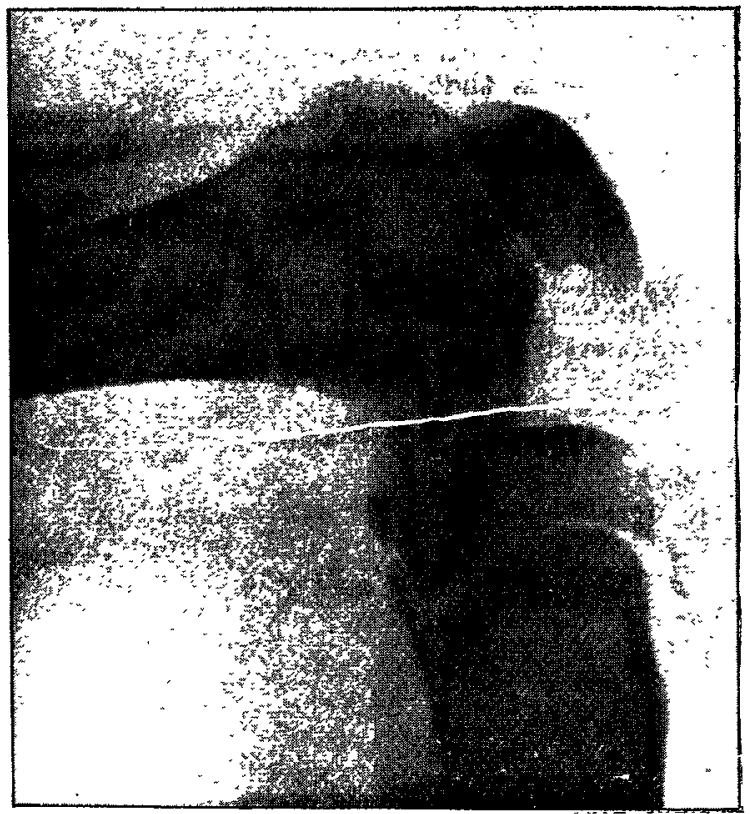

Showing considerable displacement and atrophic appearance.

This showed some gaping of the anterior half of the main junction of the upper epiphysis of the tibia, while a sharp angle existed at the junction of the main mass and the descending beak; two small ossific deposits were seen in the cartilage of the beak itself. The interval between the beak and the upper end of the diaphysis was greatly widened and the latter was more transparent than it should be beneath the space. The prominence of the lower segment of the tubercle was well developed on the diaphysis but no separate ossific centre was visible. The case was regarded as one of local osteitis and tuberculosis being suspected an exploration was recommended and carried out. The operation revealed little; the bone of the upper end of the diaphysis was abnormally soft and a little was scraped away with a Volkmann's spoon but no sign of tuberculous deposit was discovered. The wound healed and after two months of rest the boy returned to school free from any symptoms except occasional aching pain. Violent games were forbidden for the time. Two years later the boy was quite well and free from any trouble.

CASE 2. - The patient was a boy, aged 12 years. Towards the end of the football season some weakness and occasional pain were noted in the left knee. For the past six months the knee had frequently "given way" when the boy had been playing games, especially cricket. This "giving way" was attended with pain and the boy with difficulty prevented himself from falling. Two months previously some swelling was noted over the tibial tubercle and 14 days previously a symmetrical swelling was noted in the right limb also. During the whole period there had been occasional pain on movement, especially when the patient had been lying for some time in one position in bed. On examination a symmetrical swelling was observed at the level of each tibial tubercle, there were some local heat and tenderness over the swelling, and on the right side a suspicion of reddening of the skin. Neither swelling fluctuated. Skiagrams of the knees were taken by $\mathrm{Dr}$. A. H. Greg (Figs. 2 and 3 ) which disclosed the following state,

FIG. 2.

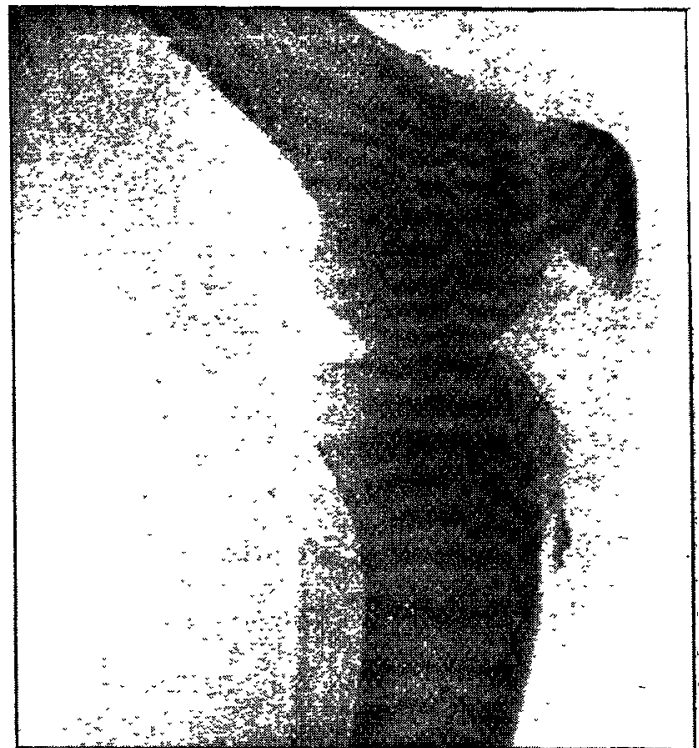

Left knee. Considerable irregularity, slight displacement.

FIG. 3.

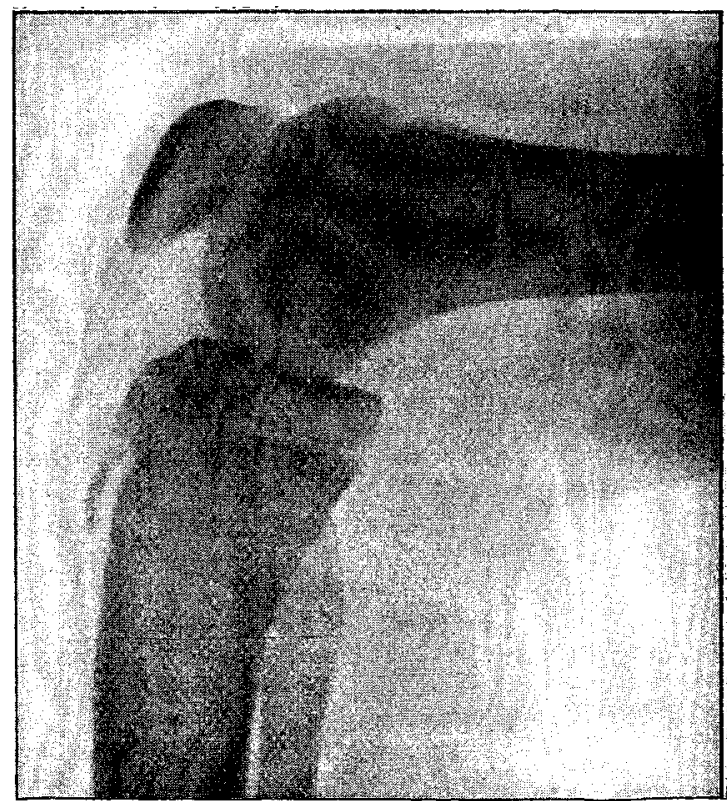

Right knee. Spiphrsis almost normal.

The gaping of the anterior part of the epiphysial junction seen in Fig. 1 was absent and the ossific granules in the beak were not so much displaced and formed a continuous line. In both beaks, but especially in the left, a well-marked interruption of the os-ific deposit existed at the junction of the beak with the main epiphysis (no obvious angle was formed here). The diaphysial prominence for the lower segment of the tubercle was absent, but the boy was only 12 years of age. Cnder the influence of rest, local rubbing, and the support afforded by a Velpeau's crêpe bandage the boy improved sufficiently in three months to return to school. violent games being for the time forbidden.

CASE 3.-The patient was a man, aged 22 years, a porter. Four years previously to his coming under observation be had received a kick from a horse on his right leg. Since 
that period the tubercle of the right tibia had been increasing in size and prominence. At intervals he suffered with pain in the tubercle and he thought that this was particularly the case when the weather was wet and damp and at nights. The knee occasionally gave way and "let him down" and kneeling caused pain. The tubercles of both tibiæ were very prominent but this was much more marked in the case of the left. There was no change in the overlying parts on either side. A skiagram (Fig. 4) taken

F16. 4.

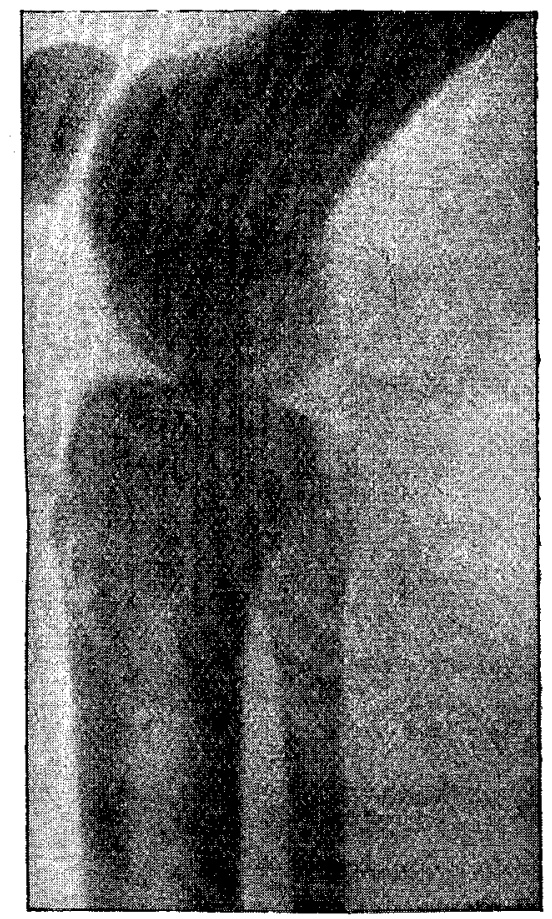

Showing complete nsplacement. Iarefaction of iulal diaphy,is.

by Dr. Greg showed the following appearances. The main epiphysis was consolidated with the shaft; in the place of the descending beak two ossific nodules at a higher level than their normal situation were seen in the substance of the ligamentun patellæ and completely distinct from the tibia. The diaphysial portion of the tubercle was well marked and beneath this and for a short distance downwards in the shaft the bone was unduly transparent and offered the appearance of a rarefying osteitis. As the tenderness and giving way were a source of much inconvenience to the patient it was decided to attempt to fix the detached tubercle. With this object a small flitp was raised from over the tubercle and an incision was carried vertically downwards through the ligamentum patellæ. The portion of bone was found to be so moveable that the incision was carried through it and a "synovial space" was then found lying between the ligament and the underlying tibia. As it was thought that simple pinning down would probably fail to insure adhesion the osseo-cartilaginous nodule was removed from the tendon and the latter was fixed by suture to the tibia. The terminal attachment of the tendon had not been interfered with. The result has been good and the patient can now kneel without pain.

The three cases related are of interest as illustrating the various degrees of development of the condition and in showing that the mischief is primarily confined to the portion of the tibial tubercle developed from the epiphysis. It may be useful to add a few words concerning the pathology and symptomatology of the condition.

As has been shown by Schlatter and others ossification of the tubercle of the tibia may be in the form of a continuous extension downwards in the tongue-like prolongation of the epiphysis, or it may follow the appearance of separate ossific nodules in the tongue itself. Further, it is evident that the lower portion of the fully developed tubercle is formed by a projection of the diaphysis at the point of junction of the lower extremity of the epiphysial beak. The latter point is well illustrated by the three skiagrams accompanying the cases. In Figs. 2 and 3 , from a boy aged 12 years, no trace of the diaphysial projection is to be seen ; in Fig. 1, from a boy aged 14 years, it is obvious; while in
Fig. 4 it forms a pronounced eminence. Its development no doubt corresponds with the increasing strain thrown. on the diaphysis with the growing strength of the quadriceps extensor.

Causation of the condition.-In Cases 1 and 3 a kick was adduced as the original cause of the trouble by the patients themselves, and in the case of the two boys it is significant that the commencement coincided with the football season. The latter fact emphasises the influence of violent contraction of the quadriceps extensor in the production of the injury. The condition falls into strict coin:cidence with the rarer one of separation of the tibial tubercle in adults and differs chiefly in the comparatively small amount of displacement of the fragments. This is no doubt to be explained by the fact that the violence has usually been insufficient to tear the lateral extensions of the quadriceps passing to the line running from the tibial tubercle to the tuberosities. The effect of rupture of these extensions in allowing free displacement of the separated tubercle has been pointed out by Osgood ${ }^{1}$ and compared with the corresponding result of free laceration of the expansions of the quadriceps and triceps respectively in fractures of the patella and olecranon. In both of the cases related above I should be inclined to relegate the result of the direct kick to the production of an excessive reflex contraction of the quadriceps due to the blow over the patellar tendon. 'This limitation of the degree of displacement is of practical importance, since it renders implication of the capsule of the knee-joint (a coincident injury seen in fracture of the adult tubercle) unlikely. Naturally the incidence of the condition is confined to adolescence and this of the early stage.

Pathological anatomy. - The influence of the mode of ossification of the tubercle has been already adverted to ; suffice it to point out that in all three of the instances under discussion the process was that of the deposit of separate nodules in the beak. The figures show well the progressive change which may take place when the condition is untreated. In Figs. 2 and 3 , in which the history was of six months' duration, slight change is to be observed beyond the evident break of contiuuity at the point of junction of the beak and main epiphysis. In Fig. 1, in which the history extended to 12 months, a well-marked angle has developed between the beak and the epiphysis, while a greatly increased distance separates the beak from the diaphysis. In Fig. 4, where the length of history amounted to four years, the beak has become entirely separated from the epiphysis, forming a kind of sesamoid bone in the patellar tendon, while the tubercle proper is formed from the diaphysis alone. The amount of separation of the beak from the diaphysis has been noted to vary considerably by other observers but whether the sequence of events shown by the above skiagrams is a common one further experience alone can prove.

Another point which deserves mention is the remarkable pseudo-inflammatory signs which are seen to accompany the injury. Thus not only are there local swelling, heat, and tenderness in the soft parts overlying and surrounding the tubercle but the underlying bone of the diaphysis also exhibits signs of rarefaction in an increased transparency. The latter is well shown in Fig. 4 and was existent also in the case forming the subject of Fig. 1, although it is not apparent in the printed skiagram. The inflammatory signs have in many cases given rise to the supposition that a local infective process was present. In a case reported by $\mathrm{K}$. Winslow ${ }^{2}$ these signs led to a negative bacteriological and inoculation test being undertaken and in Case 1 tuberculous disease was suspected by myself prior to the operation. In Case 3 the injury resulted in a very imperfect formation of the tibial tubercle, none the less the tuberclé was unduly prominent, and it is conceivable that an unduly prominent tibial tubercle may be a remote result of the injury. In this very patient a large tubercle existed in the sound limb. Unfortunately I neglected to obtain a skiagram from it.

Signs of the injury. - The most characteristic clinical indication is the "giving way" of the forcibly extended knee. This seems to be present in all cases and is the more likely to be mentioned by the patient as it is usually.antecedent to attacks of pain. The remaining clinical signs are pain, variable in amount and continuity but liable to 
occur after " giving way" of the knee or on the first movement of the limb after it has been at rest for some time in one position, as at night; local tenderness, elicited on palpation or on kneeling; swelling due to local cedema; and occasionally a suspicion of local redness of the surface. In Case 3 the tubercle was evidently moveable on palpation and manipulation of the tendon.

Treatment.--Rest and local support are the only necessary means when the cases are seen early and recognised. Counter irritation may be useful to relieve pain. Case 2 gives the probable ordinary course of the injury when taken in time.

I cannot defend the exploration made in Case 1 as it was undertaken on a mistaken diagnosis of tuberculous disease of the bone, but it certainly did no harm and I am inclined to think that it hastened the consolidation of the parts. In Case 3 the operation was indicated by the mobility of the tubercle, the long history of four years' duration, and the fact that the condition prevented the man from following his avocation with comfort. The result I consider justified the course followed.

Charles-street, W.

\section{THE PRACTICAL VALUE OF GROCCO'S PARAVERTEBRAL TRIANGLE AS A PHYSICAL SIGN FOR THE DIA- GNOSIS AND ESTIMATION OF PLEURAL EFFUSIONS. ${ }^{1}$}

By WILLIAM EWART, M.D. CantaB., F.R.C.P. Lond., GENIOR PHYSICIAN AND JOINT LECTURER IN MEDICINE AT ST. GEORGE'S HOSPITAL; SENIOR PHYSICTAN TO THE BELGRAVE HOSPITAI FOR CHILDREN.

WhENeVER the size of a pleural effusion is equal to at least a fifth of that of the pleura its diagnosis can be safely established by the major signs at our disposal if we avail ourselves of the mutual confirmation which each of them affords to the others, but when its size is much less than a fifth physical examination does not provide us with the same strict demonstration and the presence of fluid in these small collections has generally to be inferred from the conjunction of suggestive minor signs, symptoms, and clinical circumstances. This was illustrated in two men, aged 26 years and 47 years respectively, recently under my care at St. George's Hospital with small effusions which were not tapped. In the former the fluid was easily identified at first, but at the finish its remainder could not be demonstrated with certainty by the usual methods. In the latter the diagnosis was difficult; and the fluid, which never rose above the lower fourth of the pleura, was not demonstrable by them either during the earliest or during the last stage of the attack. As a fact, owing to the inaccessible position of the fundus pleuree and to its part-occupation by an organ most variable in size, we have not hitherto possessed any fine test comparable to that for small amounts of ascitic or of pericardial fluid. I am led to believe that "Grocco's sign" will now, as a rule, supply that deficiency, as it did in the cases to which $I$ have referred.

I had not realised the capabilities of this interesting sign until it occurred to me to submit it to a crucial test which $\mathrm{I}$ found it stood well. I have since then made it the basis of my routine method for the rapid diagnosis of pleural collections, large or small. The fact that it is capable of being checked as to its genuineness in each case and at any moment by the simplest procedure places it on the list of our sure signs, and raises it in respect of trustworthiness even above the analogous sign for pericardial effusion known as the "lower dorsal dull patch" ; for in the case of the latter the only crucial test with which $I$ am familiar is its disappearance with the reabsorption of the pericardial fluid. The chief analogy which obtains between these two signs is that, in both cases, the demonstration of the existence of effusion is obtained at a distance from the fluid itself.

Groeoo's sign is as follows. Whenever fluid (either pus or serum) collects within a free pleura, a paravertebral patch of partial dulness is obtainable in the other, the "dry" plenra, of triangular outline and of the shape and relative size

2 From notes of short cliniques in the wards of St. George's Hospital. shown in the diagram, which was kindly drawn for me by my able clinical clerk, Mr. W. R. Harris. The oruoial proof which I employ to test the genuineness of the triangular dulness is its disappearance when the patient assumes the lateral decubitus on the side of the effusion, and its reappear. ance immediately he sits up or turns on to the sound side This is at the same time a demonstration of the significance of the dulness, and for clinical purposes a sufficient proof that its production is due to the influence of a mobile fluid. When, however, the pleura is over-distended the mobility of the fluid is much reduced. The complete disappearance of

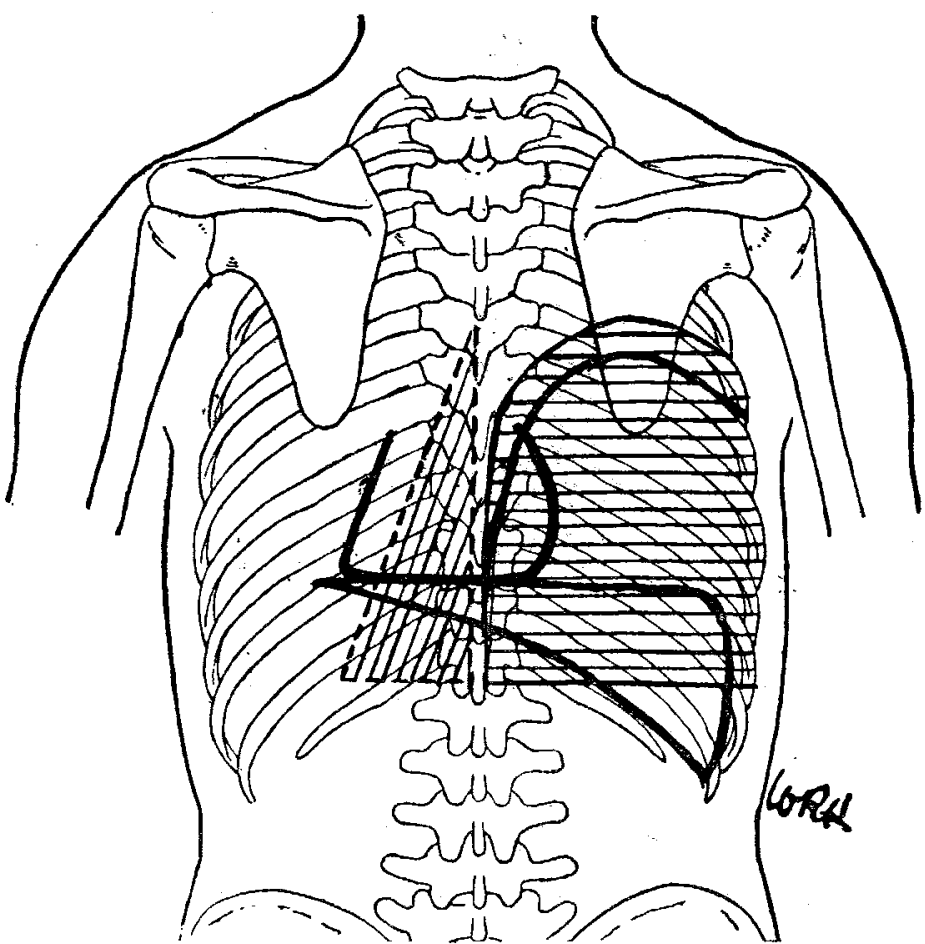

Grocco's "paravertebral triangle" of partial dulness in a case of right pleural effusion. The dorsal dulness of the heart and that of the liver are roughly indicated. The summit of "Damoiseau's curve" of pleural dulness is the level of the apex of the triangle; the relatively narrow base coincides with the twelfth rib.

Grocco's triangle does not then seem to occur, judging from one case recently examined by me, but the height of the triangle becomes much less with the change to the lateral posture.

The short routine method of differential diagnosis which I use on the strength of these observations consists in passing at once to the examination of the sound side of the back as soon as rough percussion indicates a basic dulness resembling that of effusion. If there should be no Grocco's triangle of dulness there can be no free effusion in the chest Should a Grocco's triangle be found we may then proceed to apply the crucial test if we wish to be further convinced or to convince others that the dulness is really due to fluid. The mode of percussion is a matter of indifference so long as it is good and therefore efficient.

The next question is the extent of the effusion. 'This, too, has its answer in Grocco's triangle. For whereas, as shown by Grocco, the base of the triangle, corresponding in position to the twelfth rib and to the pleural sinus, varies only slightly with the bulk of different effusions (its length ranging between three and six, or even ten, centimetres) the length of the vertical side of the triangle (and, it follows, of the third side also) varies exactly with the upper limit of the effusion. Therefore when a skilled percussor determines by two or three strokes, and with great accuracy if he should be familiar with the pleximeter, the height of the triangle and the slope of its third side, which is then to be continued from apex to base with a touch of the pencil, he has not only to demonstrate that fluid has gathered in the chest but also determine its upper level ; and he is able, even before percussing critically the effusion itself, to draw in anticipation at the level of the apex of the triangle a Damoisean's curve which confirmatory percussion will prove to be abso. lutely correct. It need hardly be pointed ont that the exact volume of the fluid within the chest cannot be measured in vertical inches of dulness and in inches of circumference. Its determination requires mathematical 